\title{
MANUAIS ESCOLARES, FORMAÇÃO DE PROFESSORES E CONCEPÇÃO CLÁSSICA DE MODERNIDADE: AS "NOÇÕES DE HISTÓRIA DA EDUCAÇÃO” DE AFRÂNIO PEIXOTO NO BRASIL NA DÉCADA DE 1930
}

\author{
School manuals, teacher training, and the classic conception of Modernity: the \\ "Concepts of the History of Education" by Afrânio Peixoto in Brazil in the 1930s
}

Manuales escolares, formación de profesores y concepción clásica de Modernidad: las "Nociones de Historia de la Educación" de Afrânio Peixoto en Brasil en la década de 1930

Bruna Aparecida Rodrigues Duarte ${ }^{2}$

Décio Gatti Júnior ${ }^{3}$

\section{Resumo}

Este trabalho comunica os resultados de investigação na área de Educação, na subárea de História da Educação, com temática vinculada à História Disciplinar cujo objeto privilegiado foi um importante manual escolar destinado à formação de professores, sob o título "Noções de História da Educação" redigido por Afrânio Peixoto, publicado em 1933, pela destacada Companhia Editora Nacional. Os combates travados no Brasil republicano, entre uma concepção de mundo liberal e outra católica ganhou centralidade em termos culturais e no âmbito educacional, sobretudo, desde a década de 1920, com forte impacto no campo legislativo, educacional e na veiculação de manuais escolares destinados à formação de professores. Neste sentido, a capacidade editorial de ambos espectros ideológicos, com vistas à veiculação em instituições escolares destinadas à formação de professores, em especial, desde a década de 1930, resultou na convivência no mercado editorial brasileiro de manuais escolares antagônicos em termos ideológicos que eram empregados em instituições escolares de instâncias promotoras do ensino também diferenciadas, em especial, estatais e católicas. O estudo detido do manual redigido pelo médico de formação Afrânio Peixoto (1876-1947) permitiu conhecer aspectos importantes do processo de renovação da educação brasileira, a partir da dimensão laica e do cientificismo presentes em sua escrita e da defesa de um papel ativo do Estado na educação escolar, que deveria ser obrigatória e gratuita, o que deixa transparecer uma aproximação com a nomeada concepção clássica de Modernidade.

\footnotetext{
${ }^{1}$ Este artigo comunica resultados do projeto de pesquisa intitulado "O manual 'Noções de História da Educação' de (Júlio) Afrânio Peixoto: a presença de um médico na escrita da historiografia da educação brasileira na década de 1930”, desenvolvido por Bruna Aparecida Rodrigues Duarte, com apoio do CNPq, sob a orientação do Prof. Dr. Décio Gatti Júnior. Pesquisa esta que se vincula a projeto de maior envergadura intitulado "Manuais de História da Educação no Brasil: entre finalidades ideais e realidades pedagógicas na formação dos educadores brasileiros no século XX”, coordenado pelo Prof. Dr. Décio Gatti Júnior, mediante apoio do CNPq e da FAPEMIG.

${ }^{2}$ Acadêmica do Curso de Enfermagem da Faculdade de Medicina da Universidade Federal de Uberlândia. Bolsista de Iniciação Científica do CNPq. E-mail: brunaap150@ hotmail.com ${ }^{3}$ Doutor em Educação pela Pontifícia Universidade Católica de São Paulo, com estágio de pós-doutorado concluído na Faculdade de Educação da Universidade de São Paulo. Professor Titular de História da Educação da Universidade Federal de Uberlândia. Bolsista de Produtividade em Pesquisa do CNPq e beneficiário do Programa Pesquisador Mineiro da FAPEMIG. E-mail: degatti@ufu.br
} 
PALAVRAS-CHAVE: Manuais escolares. Formação de Professores. Modernidade

\begin{abstract}
This paper reports the results of investigation in the area of Education, subarea History of Education, linked with the theme of the history of school subjects. The object of focus was an important school manual directed to teacher training entitled "Concepts of the History of Education", written by Afrânio Peixoto and published in 1933 by the distinguished Companhia Editora Nacional (National Publishing Company). The battles waged in the republic of Brazil between a liberal worldview and a Catholic worldview came to the fore in cultural terms and in the educational environment, especially as of the 1920s, with a considerable impact on the legislative and educational fields and in publication of school manuals directed to teacher training. In this regard, the publishing capabilities of both ideological visions, with a view toward propagation in school institutions directed toward teacher training, especially as of the 1930s, resulted in the simultaneous presence of ideologically opposed school manuals in the Brazilian publishing market. These manuals were used in school institutions engaged in teacher training that were likewise ideologically diverse, especially state institutions and Catholic institutions. From the study contained in the manual written by Afrânio Peixoto (1876-1947), who was trained as a physician, it was possible to recognize important aspects of the renewal of Brazilian education based on the lay dimension and the scientific foundation present in his writing, as well as defense of an active role of the state in school education, which should be mandatory and without charge. This reveals movement toward what is known as the classic concept of Modernity.
\end{abstract}

KEYWORDS: School manuals. Teacher training. Modernity

\title{
Resumen
}

Este trabajo comunica los resultados de investigación en la área de Educación, en la sub-área de Historia de la Educación, con temática vinculada a la Historia Disciplinar, cuyo objeto privilegiado fue un importante manual escolar destinado a la formación de profesores sobre el título "Nociones de Historia de la Educación" escrito por Afrânio Peixoto, publicado en 1933, por la destacada Compañía Editora Nacional. Las intensas disputas en el Brasil republicano, entre una concepción de mundo liberal y otra católica, gano centralidad en términos culturales y en el ámbito educacional, sobre todo, desde la década de 1920, con fuerte impacto en el trabajo legislativo, educacional y en la difusión de manuales escolares destinados a la formación de profesores. En este sentido, la capacidad editorial de ambos espectros ideológicos, con vistas a la difusión en instituciones escolares destinadas a la formación de profesores, en especial, desde la década de 1930, resulto en la convivencia en el mercado editorial brasilero de manuales escolares antagónicos en términos ideológicos que eran empleados en instituciones escolares de instancias promotoras de enseñanza también diferenciadas, en especial, estatales y católicas. El estudio detenido del manual escrito por el medico de formación Afrânio Peixoto (1876-1979) permitió conocer aspectos importantes del proceso de renovación de la educación brasilera, a partir de la dimensión laica y del cientificismo presentes en su escrita y de la defensa de un papel activo del Estado en la educación escolar, que debería ser obligatoria y gratuita, lo que deja trasparecer una aproximación con la nombrada concepción clásica de Modernidad.

PALABRAS-CLAVE: Manuales escolares. Formación de Profesores. Modernidad

A escola é um prefácio da vida. A educação na escola é a suma dos métodos sociais resumidos e selecionados, com que a sociedade prepara, nas crianças, os 
homens activos, dignos, honestos, bons, de que precisa, para viver felizmente. A educação é a "saúde" da sociedade, promovida desde a infância (PEIXOTO,

1933, p. 253)

A educação é a vida da infância na escola. A vida na oficina, na casa, nas ruas, na cidade, é, continuando, a educação dos adultos, na sociedade (PEIXOTO,

1933, p. 265)

\section{INTRODUÇÃO}

A legislação de modo geral e também aquela relacionada ao tema da educação em particular estabelece um conjunto de intencionalidades que resultam de contendas no âmbito dos intelectuais, dos educadores, dos políticos, dos homens de indústria, dos movimentos sociais, ou seja, das diferentes tendências presentes na sociedade.

No que se refere a educação, no caso brasileiro, predominou, desde o início do período republicano, a possibilidade da promoção do ensino por diferentes instâncias, o Estado, as confissões religiosas e a sociedade civil, ainda que mediante o predomínio de uma ideia de liberdade disciplinada por meio de uma legislação comum emanada do Estado, visto em sua concepção clássica, como expressão total da sociedade ${ }^{4}$. Assim, do ponto de vista da legislação, o ordenamento estatal, condicionava a vida escolar nacional de modo amplo.

Todavia, se houve intenção de homogeneizar e de uniformizar no campo legislativo e estatal, a esfera da liberdade vinculada à expressão tornou os manuais escolares artefatos culturais de grande importância nas disputas em torno de visões de mundo diferenciadas, dado que a aparente igualdade dos temas abordados nos diferentes manuais, o que pode ser observado em especial na existência de sumários coincidentes, não se sustenta diante de um minucioso exame dos conteúdos veiculados ${ }^{5}$.

Os manuais escolares, deste modo, são fontes de pesquisa histórico-educacional que evidenciavam os combates travados no âmbito cultural brasileiro, com objetivos evidentes de influenciar a formação de professores e, por meio destes, as instituições escolares que visavam formar crianças e jovens nos diferentes estabelecimentos escolares, estatais, confessionais ou da sociedade civil.

O papel instituidor das escolas poderia ter alguma uniformidade na legislação, mas, de fato, ganhava intencionalidades e tons prescritivos próprios, seja pela manutenção de instituições escolares de natureza diferenciadas, mas, também, nas diferentes visões de mundo dos autores dos manuais disciplinares, em especial, daqueles destinados à formação de professores nas escolas normais.

Para conhecer as formulações conceituais em torno da ideia de concepção clássica de Modernidade e a correspondente visão de Estado e de Educação consultar Touraine (2012).

A título de exemplo, seria interessante cotejar os conteúdos veiculados no próprio manual intitulado "Noções de História da Educação", de Afrânio Peixoto, publicado em 1933 e amplamente utilizado em escolas estatais de formação de professores, com o também exitoso manual intitulado "Educação. História da Pedagogia", das Madres Francisca Peeters e Maria Augusta Cooman, publicado no Brasil, em 1936, com ampla circulação nas instituições escolares católicas destinadas à formação de professores. Nesse sentido, para um conhecimento mais aprofundado ver a tese de Oliveira (2017). 
Figura 1. Sobrecapa da primeira edição do livro "Noções de História da Educação"6

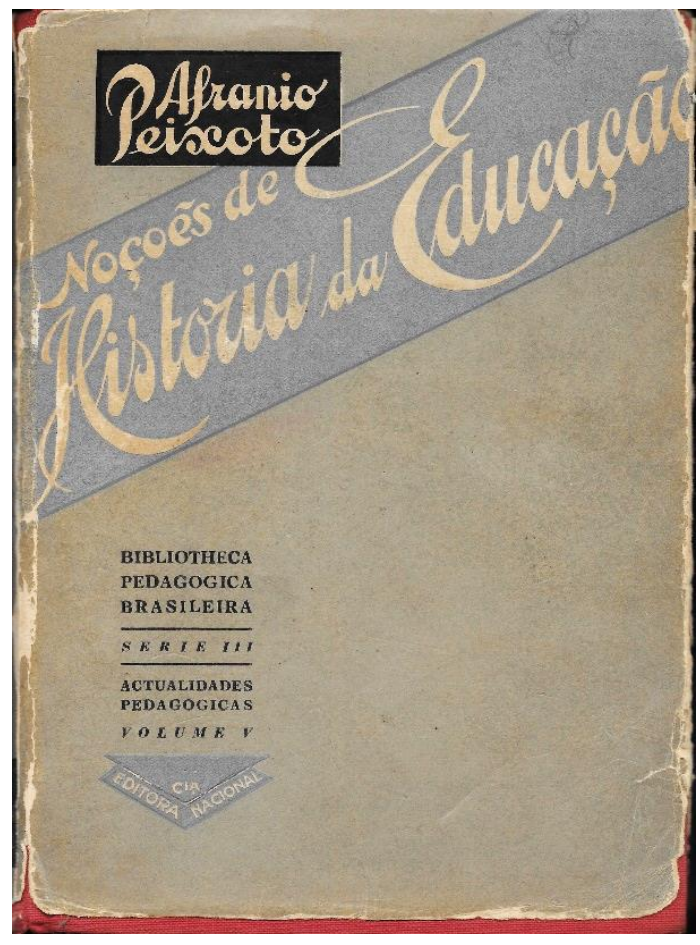

Nesta direção, o presente artigo aborda um destes autores e um destes manuais, especificamente, o intitulado, "Noções de História da Educação", redigido por Afrânio Peixoto e publicado pela Companhia Editora Nacional, em 1933, com viés republicano, laico, evolucionista e cientificista. Almeja-se apresentar o contexto histórico, a biografia do autor e o conteúdo explícito da obra, mas, devido aos limites impostos à investigação realizada, não foi possível alcançar à realidade pedagógica da efetiva utilização do manual por professores e alunos em instituições escolares ${ }^{7}$.

Para compreender Afrânio Peixoto e sua obra, a investigação comportou o levantamento, a seleção, a leitura e a análise: de bibliografia de referência relacionada à compreensão do ideal moderno veiculado por intelectuais brasileiros da primeira metade do Século XX, com destaque para o campo educacional; das obras com autoria de Afrânio Peixoto que foram publicadas no Brasil, com destaque para aquelas relacionadas ao campo educacional e histórico educacional; da bibliografia nacional relacionada ao estudo do autor.

A apresentação dos resultados da pesquisa realizada por meio deste artigo congrega três partes. Na primeira delas, aborda-se a concepção clássica de Modernidade e a educação no Século XX, com especial atenção ao Brasil. Na segunda, estuda-se a percepção de intérpretes de Afrânio Peixoto, com exame de sua vida como cidadão e suas contribuições à Educação Brasileira. Na terceira parte, apresentam-se os aspectos gerais e específicos da obra "Noções da História da Educação". Ao final coteja-se o conteúdo das

\footnotetext{
${ }^{6}$ Foi publicado por Afrânio Peixoto em 1933, no formato $14 \times 20 \mathrm{~cm}$.

Em 2016, Rosângela Maria Castro Guimarães, teve publicado um livro, no qual ela contemplou tanto a dimensão das intencionalidades, do conteúdo prescrito, quanto a realidade pedagógica do ensino de História da Educação em uma escola normal concreta. O livro tem o título "O Ensino de História da Educação na Escola Normal: entre o previsto e a realidade escolar (Uberaba, Minas Gerais, 1928-1970).
} 
obras de Afrânio Peixoto, com o das análises sobre o contexto brasileiro da primeira metade do Século XX, mas, também, com o conteúdo das análises sobre a vida e a obra do autor.

\title{
1 Concepção clássica de Modernidade e Educação
}

Touraine (2012, p. 37) afirma que a concepção clássica de modernidade compreende "a construção de uma imagem racionalista do mundo que integra o homem na natureza, o microcosmo no macrocosmo", por meio da recusa de dualismos, "do corpo e da alma, do mundo humano e da transcendência". Com o tempo, conjuga-se a isso, o evolucionismo e a ideia de progresso. Nessa direção, é interessante observar a análise feita pelo autor no que se refere à educação:

\begin{abstract}
O que vale para a sociedade, vale para o indivíduo. Sua educação deve ser uma disciplina que o liberte da visão estreita, irracional, que lhe impõem sua família e suas próprias paixões, e o abra ao conhecimento racional e à participação em uma sociedade que a ação da razão organiza. A escola deve ser um lugar de ruptura com o meio de origem e de abertura ao progresso, ao mesmo tempo pelo conhecimento e pela participação em uma sociedade fundada sobre princípios racionais. O professor não é um educador que intervém na vida privada das crianças que não devem ser outra coisa a não ser alunos; ele é um mediador entre eles e os valores universais da verdade, do bem e do belo. A escola deve também substituir os privilegiados, herdeiros de um passado rejeitado, por uma elite recrutada através de provas impessoais realizadas através de concursos (TOURAINE, 2012, p. 20).
\end{abstract}

Deste modo, a legislação poderia ser o aspecto mais racional da vontade geral roussauniana, uma espécie de consciência coletiva, à qual as consciências individuais deveriam se integrar, desde que ela resultasse de um distanciamento em relação aos interesses particulares. As instituições, por sua vez, dariam prosseguimento, em suas funções, à vontade geral, aos interesses da sociedade, sendo elas um sinal incontestável em suas finalidades e em suas práticas do bem comum sobre o qual se assentaria o exercício da cidadania.

Dentre essas instituições, a escola teria grande importância, pois abrigaria, sob seu teto, um conjunto de finalidades e de práticas, animadas por seus professores e alunos, que disseminariam os valores sociais e culturais convencionados em torno da vontade geral, da legislação, que iriam colaborar, de modo definitivo, para a transformação do indivíduo em cidadão, condição fundamental para o exercício da liberdade.

Os desdobramentos dessa ideia geral sobre a relação entre vontade geral, legislação e instituições escolares foram muitos e estiveram presentes em formulações sobre a vida em sociedade de Kant e de Hegel, por exemplo. Em ambos os casos, a ideia do bem comum estando relacionada àquilo que é bom para a sociedade, bem como de que o Estado, conforme tomado por Rousseau, ou seja, como uma comunidade de cidadãos, seria ele "o contrapeso necessário à diferenciação social que resulta da própria modernização" (TOURAINE, 2012, p. 28).

Portanto, as reformas republicanas da instrução pública, tal como foi a francesa, na segunda metade do século XIX, seriam um sinal importante de uma tomada de posição de que as instituições escolares deveriam estar vinculadas exclusivamente ao Estado, sendo vedada à iniciativa particular a oferta de instrução pública. Todavia, no caso brasileiro, 
vigorou sempre a ideia de liberdade de ensino, ainda que mediante o disciplinamento estatal.

O período que gestou esta concepção clássica de Modernidade incluiu desde o humanismo renascentista à descoberta do Novo Mundo, mas, também, a Reforma Protestante e a revolução científica. Em oposição ao teocentrismo católico, o humanismo renascentista trouxe uma concepção de mundo antropocêntrica, na qual o homem, que era visto como o pecador, o caído, o descendente de Adão, começou a ser visto, pelo viés filosófico, como a fonte real do poder.

O caráter social da vida individual foi enfatizado por Durkheim que afirmava que "um homem não se mata somente por motivos pessoais; os homens se matam mais nessa sociedade do que naquela, neste dia mais do que naquele outro..." (CHÂTELET; DUHAMEL; PISIER-KOUCHNER, 2009, p. 304). Sem dúvida, para Durkheim, indústria e a ciência afetam de forma direta a sociedade, por vezes, dificultando o acesso de alguns grupos sociais à uma vida digna, tendo como consequência o adoecimento da sociedade.

Em consonância com esta concepção clássica de Modernidade, estatal, ordenadora e vigilante, no que se refere ao Brasil, a modernidade instalada mantinha este viés dúbio, progressista por um lado, no sentido da ruptura com as tradições e os argumentos de autoridade, sobretudo, católicas, mas, ao mesmo tempo, bastante conservador, reformista e higienista, na qual se acreditava que manter a ordem gerava o progresso, mediante hierarquização, "com as elites no topo determinando e administrando as normas para a vida nacional, pública e privada” (MOTA; LOPES; CÓSER, 1994, p. 150).

Quanto a educação no Brasil, Nunes (2010) apresenta os caminhos e as dificuldades enfrentados, desde quando o patriotismo era presença marcante até sua fragilização, desde quando as escolas funcionavam em casas improvisadas até a criação de uma estrutura física moderna. Para ela, nas cidades, de diferentes formas e intensidades, as escolas foram mudando de configuração, de familiar, privada e religiosa para agregar uma rede escolar formatada pelos governos municipais.

Essas modificações intencionavam mudar muito mais que só o espaço físico, mas a pedagogia, uma renovação escolar abrangendo também a formação do professor e a visão dos pais que enviavam seus filhos para a escola. $\mathrm{O}$ espaço de aprendizagem começou a ser visto em outros lugares, além da sala de aula, tais como, "as bibliotecas, os laboratórios, a rádio educativa, os teatros, os cinemas, os salões de festa, os pátios, as quadras de esporte, os refeitórios, as ruas, as praças e os estádios desportivos" (NUNES, 2010, p. 375).

Segundo a autora, na direção de inovar a escola, há o projeto Major Vidal, que consistia em separar os edifícios escolares em "escola primária, profissional elementar, profissional secundária ou escola de artes de manufaturas, escola sanatório, escola de crianças anormais e jardim de infância" (NUNES, 2010, p. 382). O Major acreditava nessa divisão, pois tinha a escola como uma metáfora do corpo, ou seja, um corpo escolar saudável, que enxerga bem, locomove-se bem, que dá higienicamente fim aos dejetos que produz, que é controlada e que interioriza noções de ordem e asseio seria um local com boas condições físicas (NUNES, 2010, p. 382).

Rocha (2001, p. 11) trouxe a historiografia que considerou o período imperial como sombrio e sem alterações úteis do ponto de vista da educação do povo, tomando a obra "Noções da História de Educação", de Afrânio Peixoto, como um esforço em termos de ideias que visavam a modernização das mentalidades, por meio da integração da História da Educação como disciplina escolar na formação de professores. Todavia, neste momento 
inicial da República brasileira, ressaltou que também estava presente uma ideologia que aspirava ao branqueamento racial, a qual se coadunava Afrânio Peixoto, na mesma proporção que ele lutava pelos seus ideais de higienização, que poderiam acarretar o aperfeiçoamento da raça humana. Segundo Mota, Lopes e Cóser (1994, p. 150), Afrânio Peixoto era "um dos mais veementes defensores dessa aspiração, chegou a calcular que em trezentos anos os brasileiros seriam todos brancos em uma civilização latina".

\section{Afrânio Peixoto: sua vida e suas ideias}

(Júlio) Afrânio Peixoto nasceu em Lençóis, na Bahia, em 17 de dezembro de 1876, tornou-se doutor pela Faculdade de Medicina da Bahia em 1897. Nos anos de 1901 e 1902 foi preparador de Medicina Legal na Faculdade de Medicina e professor substituto de Medicina Pública na Faculdade de Direito ainda em seu estado. Pela ambição de ser professor na Universidade Federal do Rio de Janeiro, mudou para a cidade carioca, onde ampliou o seu campo de atuação, ocupando dentre outros cargos e funções: membro da Academia Nacional de Medicina (1903); Diretor do Hospital Nacional dos Alienados (1905); Professor de Medicina Legal de Higiene da Faculdade de Medicina do Rio de Janeiro (1906); Membro da Academia Brasileira de Letras (1911); Professor de Medicina Pública na Faculdade de Direito do Rio de Janeiro (1913); Diretor da Escola Normal do Distrito Federal (1915); Diretor da Instrução Pública (1916); Presidente da Academia Brasileira de Letras (1923); Deputado Federal da Bahia por dois mandatos consecutivos (1924-1930); Reitor da Universidade do Distrito Federal (1935).

\section{Figura 2. Fotografia de Afrânio Peixoto}

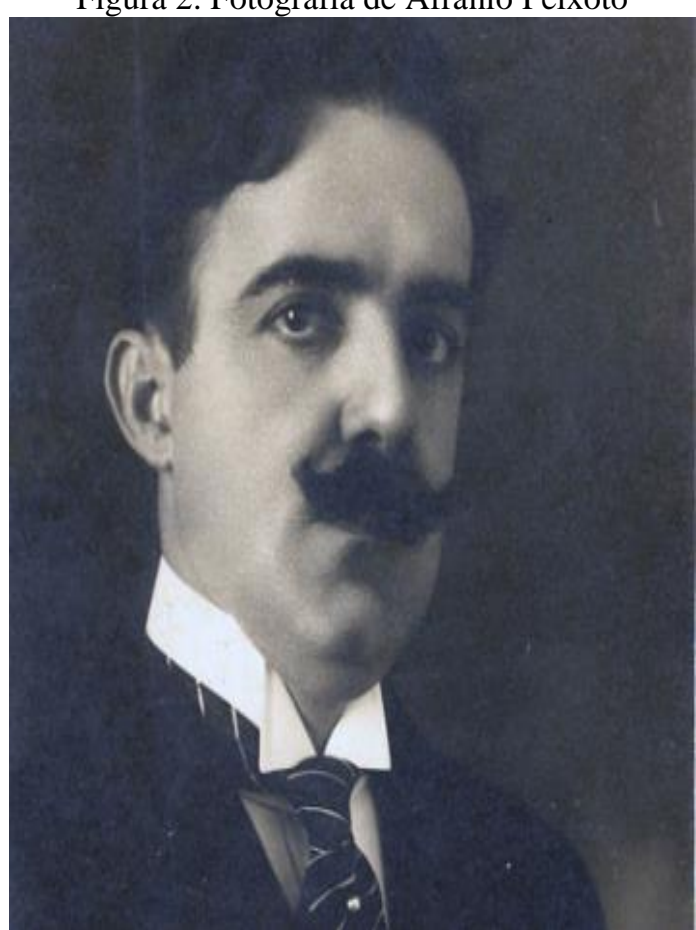

Fonte: Disponível em: < http://www.academia.org.br/a-historia-da-abl/os-arremates-de-afranio-peixoto>. Acesso em: <17 jul.2017>. 
Defendia de forma consistente a educação brasileira, de modo que o mesmo seja independente em seus conhecimentos, tendo sido um dos principais signatários do importante Manifesto dos Pioneiros da Educação Nova, de 1932, no qual consta que:

a educação nova não póde de ser uma reacção categorica, intencional e systematica contra a velha estructura do serviço educacional, artificial e verbalista, montada para uma concepção vencida. Despreendendo-se dos interesses de classes, a que ella tem servido, a educação perde o "sentido aristologico", para usar a expressão de Ernesto Nelson, deixa de construir um privilegio determinado pela condição economica e social do individuo, para assumir um "caracter biológico", com que ella se organiza para a collectividade em geral, reconhecendo a todo o individuo o direito a ser educado até onde o permittam as suas aptidões naturaes, independente de razões de ordem econômica e social. A educação nova, alargando a sua finalidade para além dos limites das classes, assume, com uma feição mais humana, a sua verdadeira funcção social, preparando-se para forma "a hierarchia democratica" pela "hierarchia das capacidades", recrutadas em todos os grupos sociais, a que se abrem as mesmas oportunidades de educação. Ella tem, por objecto, organizar e desenvolver os meios de acção duravel com o fim de "dirigir o desenvovmento natural e integral do ser humano em cada uma das etapas de seu crescimento", de accôrdo com uma certa concepção de mundo (MANIFESTO DOS PIONEIROS DA EDUCAÇÃO NOVA, 1932).

Quando atuava como médico legista e estudava sobre Higiene, ele teve como mestre Nina Rodrigues ${ }^{8}$ de quem recebeu calorosos elogios a respeito da sua tese de conclusão de curso intitulada "Epilepsia e crime", no que foi acompanhado por Juliano Moreira $^{9}$. Devido aos vários cargos pelos quais passou durante sua carreira, deixou diversas produções como, "Tratado de Higiene e Medicina Legal", obras literárias, biografias, livros sobre história, educação e política. Em 12 de janeiro de 1947 morreu de câncer, no Rio de Janeiro (MOTA; LOPES; CÓSER, 1994, p. 147-8).

(Raimundo) Nina Rodrigues nasceu na cidade de Vargem Grande, interior do Maranhão, em 1862 e morreu em 1906. Estudou na capital maranhense, no Colégio São Paulo e Seminário das Mercês, mudou-se para Salvador, na Bahia, onde ingressou no curso medicina da Faculdade de Medicina da Bahia (Fameb), em 1882, transferindo-se para Faculdade de Medicina do Rio de Janeiro em 1885, voltando para Bahia e obtido grau em 1888, com a defesa da tese "Das Amiotrofias de Origem Periférica". Em 1889, ocupou a cadeira de adjunto de Clínica Médica da Fameb, e a de diretor, em 1891, passou também pela cadeira de Saúde Pública como professor de Medicina Legal. Em termos acadêmicos, ele transitou por diversas áreas, tais como: Antropologia, Etnologia, Sociologia, Psicologia, Direito, Epidemiologia, Saúde pública, Sexologia, Criminalística e Clínica Médica. Foi precursor na expansão da área da Medicina Legal, tendo contribuído para a fundação da Sociedade de Medicina Legal, em 1894, o que provocou reconhecimento internacional e respeito por toda comunidade médica. Disponível em <http://www.bahiana.edu.br/herois/heroi.aspx?id=MTA=>. Acesso em: <18 jul. 2017>.

Juliano Moreira nasceu em Salvador - BA, em 1873 e morreu em 1933. Era negro, o que dificultou sua entrada na Faculdade, mas o que aconteceu três anos após a abolição da escravatura (1888). Sofreu preconceito por ser negro e ter baixa condição econômica. Foi um dos diretores da Fameb, tendo concluído seu doutorado em 1891, com a defesa da tese "Sífilis maligna precoce". Tornou-se professor substituto da Fameb, foi diretor do Hospício Nacional de Alienados (RJ) e deixou como legado a certeza de que pessoas com problemas mentais eram seres humanos e precisavam ser tratados como tal, com acesso a auxílio médico e não sem marginalização. Disponível em: <http://www.bahiana.edu.br/herois/heroi.aspx?id=NA==>. Acesso em: <18 jul. 2017>. 
A importância de Afrânio Peixoto no cenário educacional era perceptível, tanto que em 1935 foi convidado para o cargo de primeiro Reitor da Universidade do Distrito Federal e responsável pelas contratações de professores estrangeiros. Segundo Ribeiro (1950), Afrânio Peixoto era "uma personalidade poliédrica, rica, complexa", pois ele conseguiu realizar a junção de conhecimentos em uma obra que traz um novo método de formação para professores primários, ressaltando a importância da ligação entre a educação e higiene, o que segundo ele era essencial para que o Brasil evoluísse e assumisse o posto de país civilizado.

Em 1926, Fernando de Azevedo levanta a questão da distância entre as iniciativas paulistas no campo educacional e as fontes de cultura pedagógica internacional, o que expressa a pobreza da literatura pedagógica brasileira, a escassez de produção e, em 1931, ingressou em um grande projeto com objetivo de acrescentar na formação cultural e profissional de professores com a criação da Biblioteca Pedagógica Brasileira, da Companhia Editorial Nacional, na qual seria publicada a obra "Noções de História da Educação", de Afrânio Peixoto, com primeira edição em 1933.

A preocupação desses autores e educadores com a formação profissional, mas, também, intelectual dos professores chama a atenção, pois, eles são uma espécie de espelho para os alunos. As crianças estão em uma fase de construção da sua personalidade e junto com o conhecimento intelectual, o modo como o professor age em sala de aula, e suas concepções de vida afetam no desenvolvimento desse aluno, por isso a necessidade de uma formação de qualidade dos mestres. Segundo Peixoto, a partir de Rocha (2001, p. 34),

O que nos cumpre é preparar, hoje, o Brasil de amanhã. Educar o Brasileiro de agora para lhe dar uma consciencia de si e, portanto, dar a todos uma consciencia nacional. [...]. Contar-lhe a sua história, ou a moralidade da sua história, para que do passado algum bem possa colher e applicar, com proveito, no presente e por prevenção, no futuro.

Segundo Homero Senna, a partir de Mota, Lopes e Cóser (1994, p. 154), Afrânio Peixoto, na Bahia, era visto por seus críticos como um boêmio. Em 1900, publicou seu primeiro romance "Rosa Mystica. Symbolo Tragico".

Após assumir o cargo de preparador de Medicina Legal na Faculdade de Medicina na Bahia e professor substituto de Medicina Pública na Faculdade de Direito da Bahia, publicou sua segunda tese, que seria publicada com o título "Manual de Tanatoscopia Judiciária", em 1901. Após esses acontecimentos, o ciclo de Peixoto na Bahia estava finalizado e iniciava-se o ciclo no Rio de Janeiro.

Peixoto continuou a construção de sua carreira na cidade carioca, que, segundo Mota, Lopes e Cóser (1994, p. 156) estava infestada pela febre amarela, sem indústria, ruas ruins, os bondes funcionavam com burros e a noite quem mantinha a cidade viva eram os guardasnoturnos, os varredores de limpeza pública, os boêmios, os vagabundos, as prostitutas, os homossexuais e os marinheiros. Foi nesse cenário que sua carreira deslanchou, pois, como já foi mencionado, ele era discípulo de Nina Rodrigues na Bahia e foi apadrinhado por Juliano Moreira, também baiano, no Rio de Janeiro. Sua tese "Epilepsia e crime", de 1897, teve a atenção da sociedade médica, sendo reeditado com prefácio de Nina Rodrigues e Juliano Moreira.

Afrânio Peixoto, junto com seu padrinho, Juliano Moreira, fez uma revolução na abordagem psiquiátrica no Brasil, como a construção de casas fortes e abolição das 
camisas de força, com maior comodidade ao doente e reforma da enfermagem psiquiátrica, bem como com o estímulo ao aperfeiçoamento e a boa formação dos profissionais.

Entre 1910 e 1940, ele teve intensa produção científica e literária, com a produção de aproximadamente 140 obras, com três a oito edições, em média, e era um dos autores com maior número de leitores (VIEIRA; ROBALLO, 2007, p. 247). Suas obras destacadas no âmbito da Saúde e da Medicina foram: Medicina Legal (1911), Noções de Higiene (1918), Elementos de Higiene (1912). No âmbito político e histórico: Minha terra e minha gente (1915), José Bonifácio, o velho e o moço (1920). Também teve obras destacadas quanto a crítica, filologia e a história da literatura brasileira: Trovas brasileiras (1919), Parábolas (1920), Castro Alves - o poeta e o poema (1922), Camões e o Brasil (1927), História da literatura (1931) Panorama da literatura brasileira (1940) e Dicionário dos Lusíadas (1924) escrita com Pedro Pinto.

Dedicava-se muito ao estudo da eugenia que vinculou a várias outras áreas, tais como a produção dos seus livros sobre Medicina Legal. Publicou grandes estudos também sobre a pederástica e o defloramento. Também deixou produção na área de sexualidade. Para Peixoto, a partir de Mota, Lopes e Cóser (1994, p. 164), "se a educação dos meninos gerasse timidez sexual, isso poderia leva-los à inversão sexual", sendo que os prazeres sexuais só deveriam ser sentidos pensando no coletivo, ou seja, reprodução, e nunca só um prazer individual.

Para Vieira e Roballo (2007, p. 246), Peixoto possuía três características importantes dos intelectuais do período que eram pessoas empenhadas e engajadas na política por acreditar ser uma missão social, além de querer sempre provocar melhoras na educação/formação defendendo a sua centralidade, com propostas de mudança no período em uma busca constante de melhorias para lidar com a cultura seja ela artística, filosófica, científica ou pedagógica.

Pelo fato desses intelectuais encararem essas ações como missão social ocupavam diversos setores como imprensa, escola, Estado e de maneira intensa como Peixoto, a produção de livros. Assim, fica clara a influência que os mesmos possuíam.

Se o livro é índice de cultura, o nosso país pode já ser acreditado. Se todos não leem, quase todos os brasileiros escrevem. E acabarão por lerem, todos os que escrevem. Ao menos as próprias obras. O livro tem, pois, um futuro certo e promissor, no Brasil. Livro é progresso (PEIXOTO, 1950, p. 248).

Acreditava fielmente na cultura brasileira e assim defendia e tentava difundir a consciência nacional como também a formação educacional, afirmando que com a educação existiria a democracia, já que para exercer o direito, o homem precisa conhecer a si mesmo e aos seus deveres, sendo ignorantes aqueles que cedem seu poder de decisão e começam a servir a outros, pois, segundo Peixoto, a partir de Vieira e Roballo (2007, p. 248) "Só há um caminho para a conquista da natureza, dos homens, de si mesmo: saber. Não há outro meio de o conseguir: querer".

\section{Aspectos gerais e específicos da obra: "Noções da História da Educação", de 1933}

Segundo Vidal (2001), a obra "Noções da História da Educação", de 1933, foi o livro mais referenciado nos programas de ensino do Instituto de Educação do Distrito 
Federal em 1937. Peixoto cita no prefácio da segunda edição de sua obra, sobre a união da história da educação com a civilização, pois "a história da civilização é a história dos resultados da educação" (PEIXOTO, 1942, p. 8), não sendo possível fazer separações, já que o grau de civilização de uma sociedade condiz com sua entrega a educação.

Segundo Gondra (2011, p. 20), Afrânio Peixoto buscava contribuir para formar homens de bem, o que não parou em apenas uma produção, mas se estendeu em vários trabalhos, sempre com essa ideia de formação humana que foi discutida de várias formas em sua escrita, acreditando, assim, que a formação de um homem de bem se daria seguindo os princípios articulados na História da Educação.

Importante relatar que essa obra de Peixoto foi redigida devido a um curso ministrado por ele em 1932 no Instituto de Educação, em um programa de formação de professoras primárias, a partir de reforma liderada por Anísio Teixeira, conterrâneo de Peixoto. Inclusive o modo como o livro é produzido, as divisões de capítulos, o modo como é exemplificado é muito parecido com a estrutura do curso. "Evolutivo e linear se constituem em adjetivos facilmente empregados para definir o tipo de história praticada por Afrânio Peixoto" (GONDRA, 2011, p. 21). No curso-livro está apresentada de forma clara a cronologia e a síntese de cada matéria abordada, de forma que o leitor consiga perceber o contexto que estava o autor ao escrever.

Para Gondra (2011, p. 21), Peixoto é portador de um projeto de educação integral no qual o sujeito esteja inserido de forma moral, física e intelectual, para que os três lados sejam observados de forma igualitária, de modo a assegurar a produção de homem de bem. Sobre a questão dos sexos, onde a velha pedagogia trabalhava com aulas separadas para meninos e meninas, sendo que neste novo projeto é estimulado uma educação igualitária para meninos e meninas, com definições que aparecem na obra de Educação da Mulher. (PEIXOTO, 1947). O último lado desse quadrilátero vem na formação do corpo docente, sendo que Peixoto advogava que na educação das crianças, as mulheres possuíam mais habilidades no desenvolvimento, assim os homens deveriam ir trabalhar em outro momento na educação. 
Figura 3. Exemplo de sincronismo presente nas "Noções de História da Educação" 10

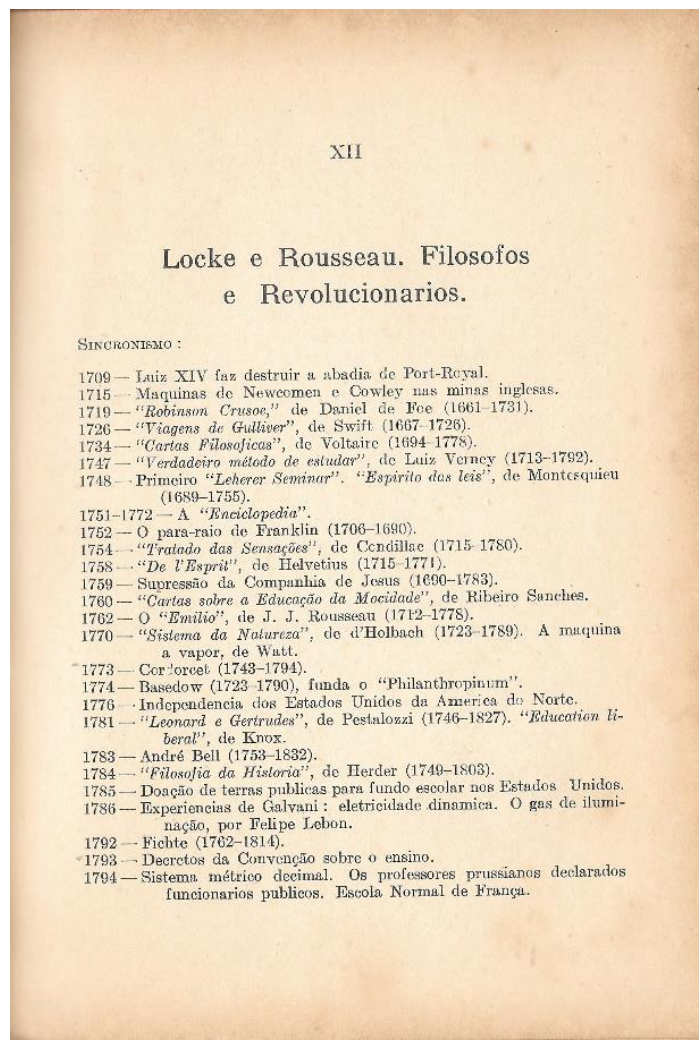

De forma mais específica ficaram perceptíveis algumas diferenças quanto as características gerais da obra relacionadas as atuais, como, o sumário apresentado no fim da obra, a presença de quadros sincrônicos em cada capítulo, ou seja, fatos que ocorreram no mesmo período do tema apresentado, o que facilita a compreensão, e outro fato que confirma a preocupação de Peixoto em saber que os leitores entenderiam o que escrevia, é que além desses meios, também aborda cada uma das personagens importantes em cada período. Expõe ainda ilustrações que podem ser de situações ou dos próprios personagens citados, como também aborda o mesmo tema em vários países.

O livro inicia com a apresentação da História Geral da Educação, dando ênfase à singularidade de cada povo, o que de certa forma é cotejado com a realidade brasileira. A partir da página 208, o autor aborda especificamente o Brasil, já com a base contextual firmada. Aborda a História da Educação com os selvagens primitivos, o tamanho respeito ao professor, e os meios de punição e aprendizagem existentes. Passa por alguns países tratando da educação arcaica, como na Índia, China, Assíria, Pérsia, Egito e Israel.

Alguns fatos chamam atenção, como a forma do ensino na China, onde com 6 ou 7 anos até seus 12 anos, os alunos faziam exercícios de memória, de leitura e escrita, copiando e recopiando, já na Caldéa, o conhecimento era transmitido dos pais para os filhos, e nesse local surgiu a contagem por meio do Zodíaco, sendo o ano de 12 meses, a hora de 60 minutos, o minuto de 60 segundos. Depois o Egito, propulsor da Matemática, onde foi criado o sinal de mais e de menos, a possibilidade de vários dons e ensinos. E os

\footnotetext{
${ }^{10}$ Afrânio Peixoto (1933, p. 143).
} 
judeus, grandes pensadores da educação, com a ideia de que todos deveriam tratar seus mestres com muito respeito e afetividade, dizendo também que a educação é base chave de toda uma vida, onde não existe escola e alunos, a cidade pode ser destruída.

Após essa introdução sobre a Grécia, os grandes pensadores são apresentados, iniciando por Péricles, Demóstenes, Isócrates até serem apresentados os educadores gregos, como Pitágoras, que analisava o seu aluno antes de admiti-lo já que, como dito no provérbio "Não se faz um Hermes de qualquer madeira" (PEIXOTO, 1933, p. 42) e Sócrates que acreditava na educação como uma revelação, sendo dever de um bom mestre ajudar o seu aluno a se revelar. Interessante citar que foi considerado o mais sábio da Grécia, Platão, discípulo de Sócrates que definia a educação como "A boa educação é a que dá ao corpo e a alma toda a beleza, toda a perfeição, de que são capazes". Como também outros, Xenofonte também discípulo de Sócrates e de Aristóteles, discípulo de Platão, e, por fim, Plutarco que foi muito admirado pelas suas obras como "Vidas Paralelas" e "Obras Moraes".

No decorrer da obra, o autor procura sempre cotejar o modo como se vê a educação, como ser um bom mestre, para quem ensinar e como, entre diversos pensadores e mestres do período. Em Roma, a educação começa em casa, só depois os mestres entravam em ação, e a punição existia e era severa, vara e até açoites aos alunos que não respeitavam seus professores. Não eram todos que mereciam serem ensinados, assim, não era universal o ensino.

A escolástica, filosofia da Idade Média se inicia, assim como construção de belíssimas universidades onde aconteciam debates calorosos acerca de determinado assunto, sempre com diferentes formas de ver, nas quais cada um teria que convencer que está certo. Desse período em diante assistimos com clareza que as ideias começam a se propagar, com Descartes impulsionando a dúvida e o questionamento.

Rousseau trouxe emoção e questionamentos, impulsionando a revolução contra a civilização do Antigo Regime. Acreditava que o mestre deveria proteger a criança do próprio ensino, da família e da sociedade, o ensino deveria ser amável e constituído para a melhora do homem. Cada atividade em seu tempo, sem roubar a infância da criança, só acompanhe sua evolução e aos poucos de acordo com sua mentalidade, forneça $o$ conhecimento. Pestalozzi e Froebel chegam com ideias parecidas, já que ambos acreditavam em uma educação com amor e que liberte, acreditam também que o mestre deveria se dar totalmente aos seus alunos, e ajuda-los na aquisição desse conhecimento. 
Figura 4. Exemplo de ilustração, neste caso, sobre a obra Emílio de Rousseau presente nas "Noções de História da Educação"11

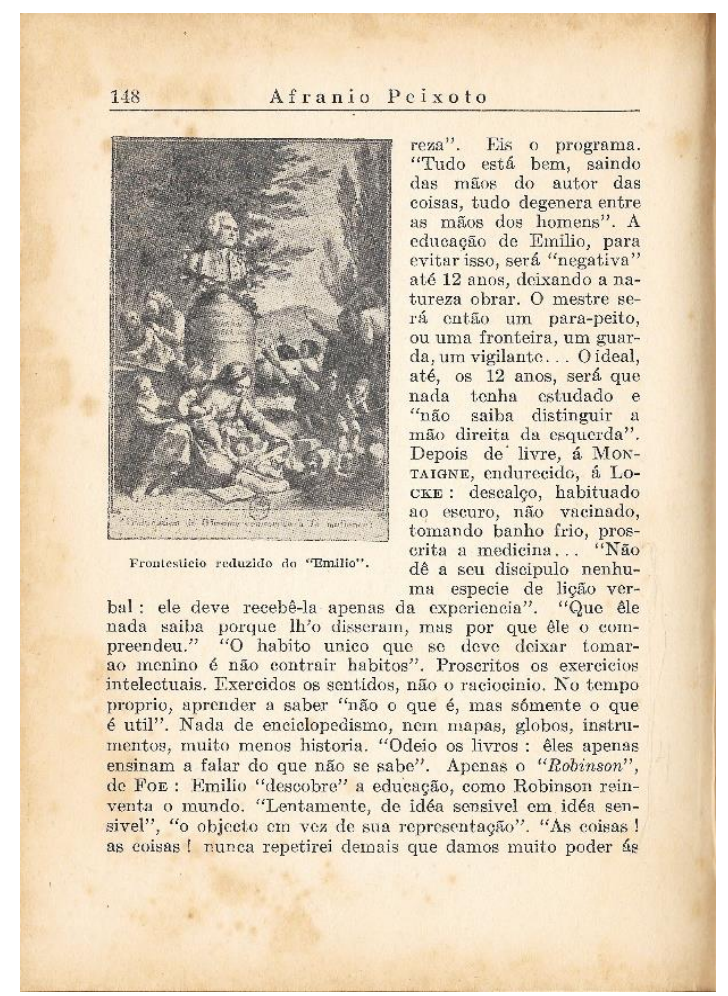

Stuart Mill, diferente dos educadores que tinham sido examinados anteriormente na obra, conferia centralidade à ciência, não era adepto ao sentimentalismo, tanto conhecimento e trabalho o fez altruísta, acreditava que era necessário formar o homem, para depois o formar dentro de uma profissão.

Peixoto faz uma relação nos Estados Unidos de Mann à Dewey, passando assim pela educação que Mann acreditava, que era sem castigos, sem prêmios, dando oportunidades para que o aluno cresça e o mais importante de tudo observando sua força de vontade, sua paixão em aprender, para ele, não muda em nada a criança ser inteligente, se não tem o desejo de saber mais. Interessante citar também, que nesse período as mulheres começaram a ter, o que chamaram de vocação para dar aulas em classe primária, o que não era bom o homem fazer.

James defendia a associação de conhecimento, ou seja, não focar tanto na memória fotográfica, mas sim, relacionar um saber ao outro, isso faz com que não se apague fácil da memória, e se torne realmente um aprendizado. Já Dewey, acreditava que o aprendizado só era válido com a ação, teoria e prática sempre relacionados "O homem não é feito para contemplar o mundo, mas para dar-lhe uma forma, continuando conscientemente a obra da natureza" (PEIXOTO, 1933, p. 199).

Finalizando essa passagem significativa por vários países, conhecendo a educação de diferenças formas, e seus principais momentos e evoluções, vamos analisar agora o

\footnotetext{
${ }^{11}$ Afrânio Peixoto (1933, p. 148).
} 
Brasil, onde Peixoto aborda os aspectos da educação e salienta sobre a Escola Nova em um capítulo.

No período colonial os principais educadores no Brasil, os que detinham do poder de decidir sobre o modo de ensino, eram os jesuítas, que optaram por uma educação que formasse um homem universal, humanista e cristão, nunca, crítico.

Assim o objetivo maior era expandir o catolicismo, fazia-se uso do castigo, da palmatória e, de certa forma, modificaram a cultura dos indígenas. Três padres são considerados como símbolos da educação no Brasil, pois foram os primeiros professores, sendo, João de Azpilcueta Navarro, José de Anchieta e Antonio Blasquez.

Em 1556, foi criado o $1^{\circ}$ colégio também chamado de convento, em Piratininga, São Paulo. Interessante mencionar que em menos de vinte anos dessa nova população no Brasil, já se tem mudança na vida dos indígenas, onde não havia mais canibalismo, os filhos aprendiam a ler e escrever, e pediam por isso. (PEIXOTO, 1933, p. 216).

Em 1759, a Companhia de Jesus foi expulsa. Iniciou assim a primeira reforma de ensino, de muitas que vieram até hoje. Até esse momento na História a Educação era mantida pelos impostos de alimentos vendidos, o que foi modificado, tendo assim valor fixo e privativo, para escolas chamadas de régias.

O problema de falta de pagamento, diminuição de professores já começou nesse período. Peixoto comenta: "A instrução estava fechada em estreito círculo e péssimas eram as escolas, porque não eram bons os professores" (PEIXOTO, 1933, p. 218).

Com o início da Monarquia, o Projeto de Constituição foi apresentado em Primeiro de Setembro de 1823, no qual se estabeleceu a existência de escolas primárias e universidades suficientes e sem abusos, com o intuito de uma educação popular e de qualidade.

Para um Brasil feliz, a sua mocidade deveria ser educada, só assim poderia ser livre. Introduziu-se o ensino mútuo ou lancasteriano. Mas como já era esperado, em 1833, admite-se que o ensino mútuo não atingiu a meta prevista, assim, o governo não o manteria mais.

Em 16 de junho de 1826 surgiu um projeto de lei sobre a instrução pública, o qual foi assinado por Januário da Cunha Barbosa, José Cardoso Pereira de Melo e Antônio Ferreira França. Assim, no Brasil, dividir-se-ia o ensino em quatro graus. No primeiro, por exemplo, aprender-se-ia a ler, escrever, princípios e regras de aritmética, os conhecimentos morais, físicos e econômicos. O método seria próximo ao lancasteriano.

Foi legislada a proibição do castigo corporal pelo Senhor Batista Pereira, que teve oposição, de Holanda Cavalcanti que mencionara que na educação presente ninguém conseguiria ensinar sem o uso da palmatória, mas, mesmo assim, a proibição continuou. Além disso, emergiu um novo debate, no qual Ferreira França defendia que as mulheres deveriam ter preferência a ministrar aula ao magistério das escolas públicas de primeiras letras.

Peixoto traz de forma resumida, o conteúdo do Ato Adicional de 1834, já que a lei de 1827 falhou, devido à falta de professores. Os decretos foram se renovando e mudando de acordo com a evolução do pensar de cada um, envolvendo o ensino primário, o governo federal e as universidades. 
A educação no Brasil foi vista como uma das mais abandonadas, pois a qualidade não estava da forma que necessitava, mas D. Pedro II destinou o recurso financeiro que seria utilizado para erguer uma estátua em sua homenagem para construir edifícios escolares. Os dois mais bonitos edifícios escolares até então na capital brasileira.

O Ministério da Instrução Pública, desejo da Monarquia, foi criado na República com Benjamin Constant. O decreto n. 981 de 9 de novembro de 1890 reformou a instrução nacional em relação a classe primária, que se declarou livre e gratuita, com mais disciplinas, mais classes, mais edifícios. Peixoto (1933, p. 237) cita uma síntese da educação pública muito interessante escrita pelo pedagogo José Verissimo em 1900, a saber:

\footnotetext{
Nosso ensino público, nunca houve alma, espírito, Idea; não lhe faltaram porém, jamais, longos, minuciosos, pomposos regulamentos. Neles se refletia sobretudo a pouca competência em geral dos legisladores, e um amálgama incongruente de bons e maus princípios, de idéas sãs e falsas, de pouca adaptabilidade ao nosso meio de condições, tudo copiado com a pouca reflexão e espírito prático dos livros estrangeiros sobre o assunto ou imitado sem discernimento do que no exterior se praticava.
}

Os dados do censo desse período são alarmantes, pois, em cada 1000 brasileiros, 745 são analfabetos e 255 sabem ler e escrever. As estatísticas quanto a número de escolas, alunos, para cada habitante geral eram ainda muito desanimadoras. Peixoto procurou fazer comparações também com outros lugares, como Hawai, considerado um dos estados americanos de menor importância. 
Figura 5. Exemplo de apresentação de dados estatísticos, neste caso, sobre o analfabetismo no Brasil em 1920, que está presente nas "Noções de História da Educação" 12

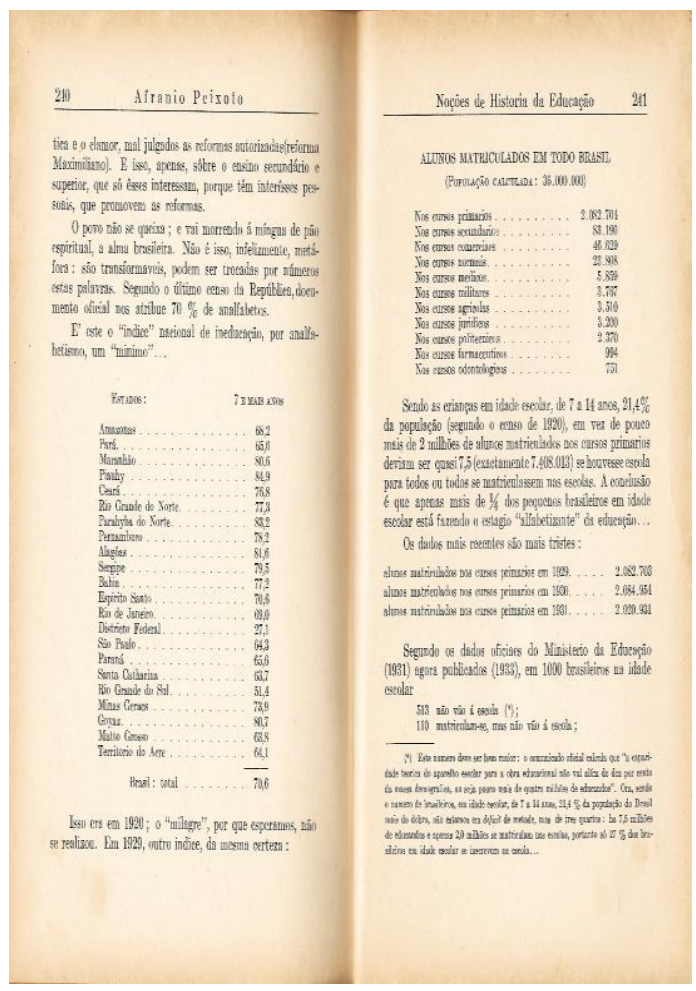

Figura 6. Exemplo de apresentação de dados estatísticos, neste caso, sobre as matrículas escolares no Brasil em 1929, que está presente nas "Noções de História da Educação" 13

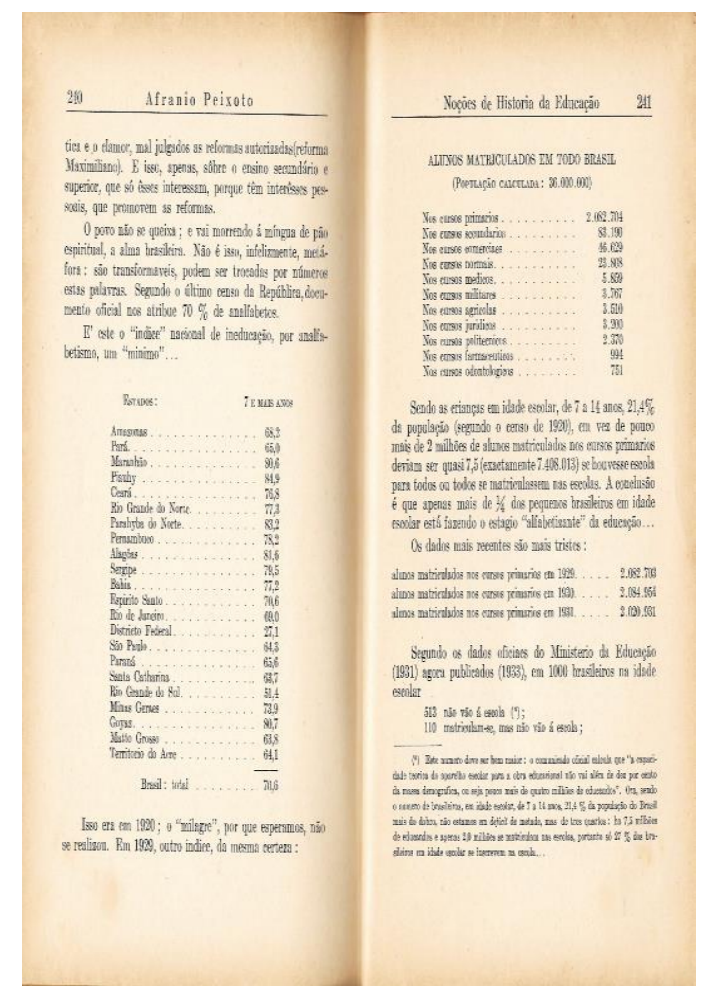

Ao final do livro, Peixoto cita nomes de alguns educadores que contribuíram com a educação, sendo alguns religiosos, como João de Aspilcueta Navarro, que veio ao Brasil com o Padre Manoel de Nobrega, em 1549, sendo o primeiro educador brasileiro, primeiro missionário do Gentio, um dos primeiros bandeirantes e também o primeiro jesuíta a aprender a língua indígena, traduzindo assim orações, mandamentos e outros, José de Anchieta, que formou em Coimbra e foi designado para ser missionário no Brasil, foi professor de alunos índios e filhos de reis, publicou poemas, ensinou gramática e traduziu para os índios, foi considerado o iniciador da literatura brasileira, apóstolo e educador do Brasil e Antonio Blasquez, castelhano, educador, dizia que quem aprende a ler, aprende toda a gramática. E outros que não eram religiosos, mas que também se empenharam nessa construção educacional, como, José Lino Coutinho, baiano, médico com formação em Coimbra, foi deputado, autor do famoso Manifesto de 22 de outubro de 1822.

Abílio Cesar Borges estudou humanidades e medicinas no Rio de Contas, onde nasceu, foi diretor geral de instrução pública, então descobriu sua vocação, fundou assim um colégio que ganhou seu nome. Era contra os castigos corporais, por isso aboliu do seu colégio, e defendia o ensino obrigatório com a liberdade de ensino, inovou a literatura, com muitas obras apreciadas.

\footnotetext{
12 Afrânio Peixoto (1933, p. 240).

13 Afrânio Peixoto (1933, p. 241).
} 
Joaquim José de Menezes Vieira formou-se também em Medicina como vários desses educadores, quando ainda estudava, foi contratado para ensinar à escrita. Fundou um colégio que foi notado, pois trouxe mudanças na pedagogia das suas viagens a Europa, também possui muitas obras.

Rui Barbosa formou-se em Direito em São Paulo, jurista, jurisconsulto, publicista, foi grande orador de causas liberais, parlamentar, ministro, senador, embaixador, jornalista, polemista e autor de obras notáveis. Antonio Augusto de Azevedo Sodré, formado em Medicina. Considerado educador pragmático, apoiou várias reformas institucionais, escolares e foi fundador do ensino agrícola.

Em seguida, Peixoto aborda a educação e a escola nova, que são conceituadas como algo melhor que o antigo, mas que também poderia envelhecer, sendo que esse movimento ocorreria pela necessidade de se ter uma educação renovada, que construísse um conhecimento fazendo com que a criança se torne um adulto adaptado e também inovador.

Ressalta-se que Afrânio Peixoto não teve como intuito descrever a filosofia da escola nova, pois, segundo ele, Anísio Teixeira e Fernando de Azevedo explicavam-no muito bem, e sim, apenas apontar indicações históricas. Esse movimento só foi possível devido ao entendimento da Biologia e da Filosofia, que proporcionaram conhecimentos dos pensadores sobre até onde o homem pode ir, e assim ir à procura do melhor, a saber: "É o ponto de partida; o de chegada é a homogeneização da sociedade" (PEIXOTO, 1933, p. 254).

Figura 7. Exemplo de reprodução de fotografia, neste caso, com os pioneiros da educação nova, presente nas "Noções de História da Educação"14

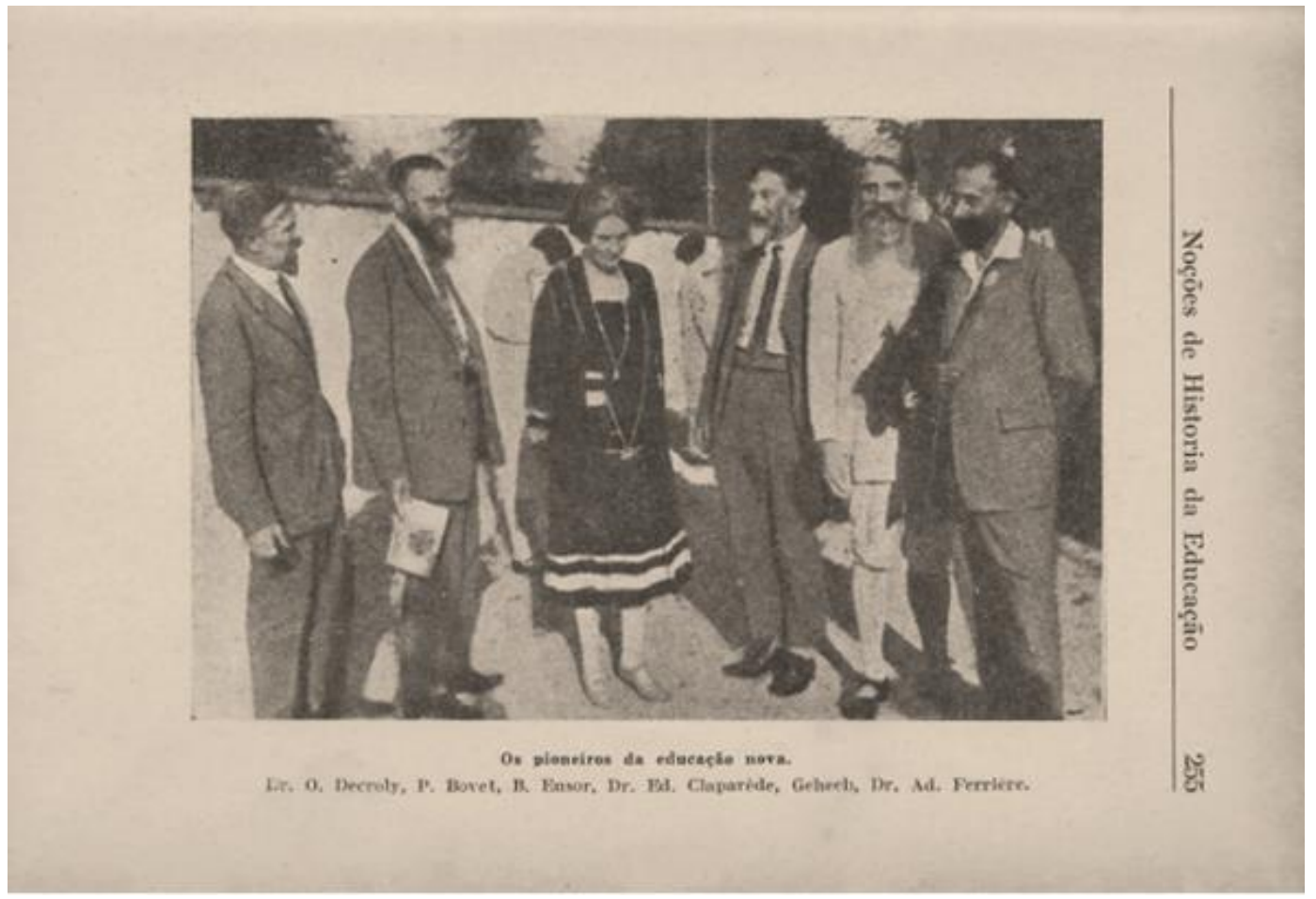

\footnotetext{
${ }^{14}$ Afrânio Peixoto (1933, p. 255).
} 
A psicologia experimental também teve sua parcela, já que ali foi analisado entre os sistemas empíricos de experimentação que nada existe na inteligência que não tenha sido interessada, estimulada. A razão é o alvo. O que antes passava pela escola, agora é o eixo, o questionador é o aluno, para que assim aconteça a multiplicação, a soma, a problematização, logo, a construção do próprio conhecimento.

\section{CONSIDERAÇÕES FINAIS}

Ficou evidenciado a importância do exame dos manuais escolares, em especial, daqueles relacionados à formação de professores, para compreensão das ideias em circulação em uma determinada época, bem como para perceber a forma dos combates em torno de visões de mundo divergentes que ocorriam no Brasil na primeira metade do século $\mathrm{XX}$, à semelhança de outros países, entre pressupostos liberais e doutrinas religiosas, no presente caso, o catolicismo. Evidentemente, dados os limites da investigação não foi possível examinar a forma como o manual era empregado e o nível de apropriação pelos estudantes no tempo, o que, sem dúvida, poderia ser tematizado em investigações futuras.

Todavia, no que se refere ao que se prescrevia para o ensino de História da Educação, ao menos no campo liberal e republicano brasileiro, o exame do manual escolar "Noções de História da Educação", redigido por Afrânio Peixoto e publicado em 1933, oportunizou desvelar os elementos constitutivos de uma visão de mundo que se expandia por todo lado, portadora de ideias políticas que continham elementos laicos, republicanas e em busca da construção da democracia, conjugada à pressupostos cientificistas e evolucionistas, com valorização dos aspectos biológicos tanto no exame da natureza quanto da vida social, o que incluía seus aspectos educativos e formativos.

Este naturalismo une-se às descobertas da psicologia experimental e às nascentes aquisições da abordagem sociológica da vida social. Em alguns casos, com estímulo a concepções progressistas e democratizantes, em outros, com viés bastante conservador, que animava posições eugênicas e racistas.

Nesse contexto, alia-se uma concepção clássica de Modernidade, na qual há confiança no Estado como potência na qual se resolvem os dissensos da vida social, com a escola pública obrigatória e, por isso mesmo, gratuita, preparando as mentalidades científicas e o espírito democrático entre crianças e jovens em busca da vida adulta, profissional, cidadã e feliz.

O empreendimento que fomentou a educação nova e a fez disseminar-se em termos mundiais encontrou eco no Brasil, com divulgação bastante presente nos meios intelectuais e políticos brasileiros, por meio de uma indústria cultural que se iniciava no país, sobretudo, na forma de periódicos e de manuais escolares, como bem se pode exemplificar na análise deste de Afrânio Peixoto, publicado em 1933, intitulado "Noções de História da Educação”.

\section{REFERÊNCIAS}

CHÂTELET, F.; DUHAMEL, O.; PISIER-KOUCHNER, E. História das Ideias Políticas. Tradução Carlos Nelson Coutinho. Rio de Janeiro: Zahar Editora, 2009. 
GONDRA, J. Temperar a alma, retemperar os músculos: corpo e História da Educação em Afrânio Peixoto. Pro-Posições. v.22, n.3, p.19-34. 2011.

GUIMARÃES, R.M.C. O Ensino de História da Educação na Escola Normal: entre o previsto e a realidade escolar (Uberaba, Minas Gerais, 1928-1970). Uberlândia/MG: Edufu. 2016.

\section{MANIFESTO DOS PIONEIROS DA EDUCAÇÃO NOVA (1932) E DOS EDUCADORES (1959). Disponível em: \\ <http://www.dominiopublico.gov.br/download/texto/me4707.pdf >. Acesso em: <17 jul. $2017>$.}

MOTA, J.A.C.; LOPES, E.M.T.; CÓSER, S.M.L. Júlio Afrânio Peixoto (1876-1947) Ensaio Biográfico. In: HERSCHAMANN, M.M; PEREIRA, C.A.M. (Orgs.). A invenção do Brasil Moderno - Medicina, Educação e Engenharia nos anos 20-30. Rio de Janeiro: Rocco, 1994. p. 147-201.

NUNES, C. (Des) Encantos da Modernidade Pedagógica. In: LOPES, E.M.T; FARIA FILHO, L.M.; VEIGA, C.G. 500 anos de Educação no Brasil. 4. ed. Belo Horizonte: Autêntica, 2010. p. 371-398.

OLIVEIRA, S.M. A presença católica na formação de professores no Brasil: os manuais das Madres Peeters e Cooman. 2017. Tese (Doutorado em Educação) - Programa de PósGraduação em Educação. Faculdade de Educação. Universidade Federal de Uberlândia. Orientador: Décio Gatti Júnior.

PEETERS, F.; COOMAN, M.A (Madres). Educação. História da Pedagogia. São Paulo: Companhia Melhoramentos. 1936.

PEIXOTO, A. Eunice ou A Educação da Mulher. Rio de Janeiro, São Paulo, Porto Alegre: W.M. Jackson, Inc, 1947.

PEIXOTO, A. Noções de História da Educação. São Paulo: Companhia Editora Nacional, 1933.

RIBEIRO, L. Afrânio Peixoto. Rio de Janeiro: Conde, 1950.

ROCHA, H.H.P. Recordação para professoras: a História da Educação Brasileira narrada por Afrânio Peixoto. In: GONDRA, J.G. (Org.). Dos arquivos à escrita da História: a educação brasileira entre o Império e a República. Bragança Paulista: Editora da Universidade São Francisco, 2001, p. 11-36. 
TOURAINE, Alain. Crítica da Modernidade. Tradução Elia Ferreira Edel. 10. Ed. Petrópolis: RJ. Editora Vozes. 2012.

VIDAL, D.G. O exercício disciplinado do olhar: livros, leituras e práticas de formação docente no Instituto de Educação do Distrito Federal (1932-1937). Bragança Paulista: Universidade de São Francisco, 2001.

VIEIRA, C.E.; ROBALLO, R.O.B. História e História da Educação no projeto de formação de professores na década de 30 no Brasil: problematizando as noções de Afrânio Peixoto. Inter-Ação. v.32, n.12. p. 243-259. 2007.

Recebido: 22/03/2017

Aprovado: 20/04/2017 